\title{
Sociedade Civil, Instituições Participativas \\ e Representação: Da Autorização \\ à Legitimidade da Ação
}

\author{
Leonardo Avritzer
}

\begin{abstract}
participação política no Brasil democrático tem sido marcada por A dois fenômenos importantes: a ampliação da presença da sociedade civil nas políticas públicas e o crescimento das chamadas instituições participativas. Do lado da sociedade civil, diversos atores pertencentes a esse campo político reivindicaram, desde o final do período autoritário, uma maior presença em instituições encarregadas da deliberação sobre políticas públicas nas áreas da saúde, assistência social e políticas urbanas (Coelho, 2004; Cunha, 2004; Avritzer, 2006; no prelo). Tal reivindicação gerou uma série de formatos híbridos caracterizados pela presença de instituições com a participação da sociedade civil e de atores estatais nas áreas de assistência social, saúde, meio ambiente e políticas urbanas (Coelho et alii, 2006; Abers e Keck, 2006). Essa presença foi acentuada nos últimos governos, que legalizaram diversas formas de inserção de associações da sociedade civil nas políticas públicas. Essas instituições foram analisadas, até esse momento, sob a ótica do aumento da participação. De fato, existem mais conselheiros no Brasil do que vereadores e, em alguns casos, como o do orçamento participativo, a participação em alguns anos alcançou a marca de quase 180 mil pessoas ${ }^{1}$. No entanto, à medida que o envolvimento da sociedade civil nas políticas sociais aumentou, um problema tornou-se inescapável: o surgimento de novas formas de representação ligadas a ela.
\end{abstract}

DADOS - Revista de Ciências Sociais, Rio de Janeiro, Vol. 50, n-3, 2007, pp. 443 a 464. 
As instituições participativas que emergiram no Brasil democrático implicaram em um aumento da representação (Gurza Lavalle, Houtzager e Castello, 2006), seja pelo fato de que os próprios atores sociais passaram a se denominar representantes da sociedade civil, seja por que o Estado passou a lidar institucionalmente com uma representação oficial da sociedade civil. Por aumento da representação, entendo o crescimento das formas como os atores sociais exercem, nessas instituições, a apresentação de certos temas, como a saúde ou interesses urbanos e o fato de que, em instituições como os conselhos de políticas, alguns atores são eleitos com o intuito de exercerem o papel de representantes da sociedade civil. Não é difícil, no entanto, perceber que a representação realizada pelos atores da sociedade civil é diferente daquela exercida na instituição representativa por excelência, isto é, no Parlamento. Dois aspectos diferenciariam a representação nas instituições participativas da parlamentar: em primeiro lugar, não há o requisito explícito da autorização, tal como elaborado por Hobbes e, posteriormente, desenvolvido por Hanna Pitkin. Em segundo lugar, não há estrutura de monopólio territorial na representação realizada por atores da sociedade civil, assim como não há o suposto de uma igualdade matemática entre os indivíduos que dão origem à representação ${ }^{2}$. Pelo contrário, a representação exercida pela sociedade civil é pluralista e, mesmo quando coincide com um território determinado em uma estrutura de conselho, ela também se superpõe a outras formas que, em geral, tomam decisões vinculantes em relação ao mesmo tema, no mesmo território. Nesse sentido, a representação realizada pela sociedade civil lembra mais a estrutura medieval de superposição simultânea de diversos tipos de representações (Gierke, 1987) ${ }^{3}$ do que a estrutura monopolista própria à modernidade (Pitkin, 1967; Mansbridge, 2003). Assim, na maior parte das vezes, a representação da sociedade civil é um processo de superposição de representações sem autorização e/ou monopólio para o exercício da soberania.

A pergunta colocada para essas novas formas desencadeadas pela ação da sociedade civil é a seguinte: seria essa proliferação de formas de representação social uma distorção do próprio funcionamento da representação ou seria apenas um caso entre muitos outros que tem servido para reelaborar a própria noção de representação, os outros sendo as formas de superposição da representação na Comunidade Européia (Held, 1995; Cohen e Sabel, 2005), assim como a ação internacional de organizações não-governamentais - ONGs como a Anistia Internacional e o Greenpeace? A julgar pela proliferação recente de uma literatu- 
ra importante que reexamina a questão sob essa ótica (Abers e Keck, 2006; Mansbridge, 2003; Urbinati, 2006a; Warren e Castiglioni, 2006; Dryzek e Niemeyer, 2006), a resposta que ofereço a essa questão é que vale a pena reexaminar os fundamentos da discussão à luz dessas novas práticas. Este artigo terá três partes: em uma primeira, reexaminarei os fundamentos do debate sobre representação, tal como foi abordado por Hanna Pitkin e consolidado na teoria democrática contemporânea. Discutirei seus principais elementos: o pressuposto da autorização, a vinculação entre representação e eleição, a idéia do monopólio e o argumento da territorialidade. Em uma segunda parte, abordarei criticamente três análises recentes que procuram lançar uma nova luz sobre a questão: a tentativa de Gurza Lavalle, Houtzager e Castello de defender uma concepção de representação virtual baseada em Burke, a tentativa recente de Nadia Urbinati de propor uma forma não-eleitoral de representação baseada na idéia de Condorcet de extensão temporal e, em terceiro lugar, a tentativa de John Dryzek de defender uma idéia de representação discursiva. Na parte final deste artigo, proporei um conceito de representação relacional, no qual tentarei, ao mesmo tempo, dissociar representação de autorização e associá-la a um vínculo simultâneo entre atores sociais, temas e fóruns capazes de agregá-los.

\section{UM REEXAME DA TEORIA DA REPRESENTAÇÃO DE HOBBES A HANNA PITKIN}

A moderna teoria da representação está baseada em três elementos: a autorização, o monopólio e a territorialidade. Com o intuito de rever esses três elementos, discutirei, nesta seção, a idéia de autorização na teoria da representação. Em seu livro clássico sobre o assunto, Hanna Pitkin adotou uma dupla estratégia de reconstrução do conceito de representação: de um lado, examinou os sentidos do termo na modernidade, abordando da representação teatral e jurídica à representação política; de outro, realizou um trabalho histórico institucional de reconstrução da maneira como a representação política se institucionalizou na modernidade. O conceito defendido pela autora será o resultado do cruzamento das duas estratégias de construção conceitual (Warren e Castiglioni, 2006). A primeira parte da obra de Pitkin, na qual ela reconstrói a origem do termo representação na modernidade, está fortemente baseada em uma releitura de Thomas Hobbes. Hobbes, no Leviatã, procurou lançar os fundamentos de um conceito não-religioso capaz de romper com a doutrina cristã. $\mathrm{O}$ autor buscou dois fundamentos seculares para a noção de representação, um primeiro, na 
Grécia, com a idéia de prosopon, isto é, da substituição de uma pessoa por outra no teatro, e um segundo, em Roma, com a idéia do procurador em Cícero. Para este, o procurador representa o seu cliente ao desempenhar três papéis distintos: "o meu, o do meu oponente e o do árbitro" (Cícero, 1942, cap. III:104-105, tradução do autor). Em Cícero, a idéia de representação envolve dois elementos: o da identificação e o da autorização. O procurador identifica-se com a condição do representado antes de representá-lo, e isso gera uma relação de afinidade. No entanto, da maneira como ela é abordada por Thomas Hobbes, apenas a autorização adquire relevância.

Ainda no capítulo XVI do Leviatã, Hobbes faz a seguinte afirmação: "quanto às pessoas artificiais, em certos casos algumas das suas palavras e ações pertencem àqueles que as representam. Nesses casos, a pessoa é o ator e aquele a quem pertencem as suas palavras é o autor, casos estes em que o ator age por autoridade" (Hobbes, 1991:112). Temos aqui tanto os elementos principais de uma teoria da representação, quanto, ainda que menos observado pelos comentaristas, elementos importantes de uma teoria da participação. Hobbes introduz o termo ação para designar todos os atos pelos quais os autores têm responsabilidade, a qual pode ser tanto direta quanto transferida por um ato explícito de autorização. No caso da representação, o problema central é como passar a possuir as ações de um outro, debate que, como aponta Hanna Pitkin, gerou uma vertente importante de discussão sobre a legitimidade do mandato no século XIX. Hobbes, nesse caso, está interessado apenas em uma linha dessa vertente, a que dá legitimidade ao ato da autorização: "porque aquele a quem pertencem direitos e posses é chamado proprietário [...] quando se trata de ações é chamado de autor. E tal como o direito de posse se chama domínio, assim também o direito de fazer qualquer ação se chama autoridade" (ibidem). Ou seja, Hobbes reduz o problema da representação ao problema da autorização e gera uma vertente dentro da teoria democrática que irá se preocupar com apenas uma questão: teria o ator ou agente político a autorização para agir em nome dos representados? Sem entrar no mérito dessa questão que já foi bastante discutida na teoria democrática (Manin, 1997), meu objetivo aqui é chamar a atenção para o fato de esta ser apenas uma das perguntas que decorrem da afirmação de Cícero. Outra pergunta que se faz é: em quais condições os indivíduos podem representar outros indivíduos com legitimidade?

Há, também, um terceiro elemento fundamental na teoria hobbesiana da representação: trata-se da diferenciação entre o autor limitado e o 
ator livre. Hanna Pitkin atenta para uma passagem fora do Leviatã na qual Hobbes discute esse ponto e faz a seguinte afirmação: “[...] utilizamos a palavra [pessoa] corriqueiramente em inglês chamando àquele que age por sua própria autoridade, a sua própria pessoa, e no caso daquele que age pela autoridade de outra pessoa, [usamos a expressão] uma pessoa do outro" (Pitkin, 1993, cap. III:455, tradução do autor). Nesse caso, devemos nos voltar para duas questões diferentes: qual é o significado de assumir ou renunciar à posse das próprias ações; e como e quando os indivíduos devem renunciar à autoria de algumas das suas ações e quando eles não o devem fazer, assim como, quais são os tipos de ações mais passíveis de provocarem renúncias de autoria e quais são aquelas nas quais os indivíduos em geral tendem a manter a sua autoria. Evidentemente, esse não foi um problema que preocupou Thomas Hobbes, posto que estava interessado unicamente em estabelecer que o ato de transferência da autoria é um ato legítimo e, enquanto tal, capaz de fundar o poder soberano legítimo.

\footnotetext{
"Quando o ator faz um pacto por autoridade, obriga através disso o autor, e não menos se esse mesmo o fizesse, nem fica menos sujeito às conseqüências do mesmo. Portanto, tudo o que se disse sobre a natureza dos pactos entre os homens em sua capacidade natural é válido também para os que são feitos por seus atores, representantes ou procuradores [...]" (Hobbes, 1991:112).
}

Certamente, no que diz respeito à representação, o problema hobbesiano limita-se ao ato de provar a legitimidade dos pactos e acordos assinados pelos representantes dos atores. Mas nós, autores da modernidade tardia, não necessitamos parar onde Hobbes parou e, nesse caso, é possível perceber que o autor do Leviatã nos dá pistas para pensar duas questões centrais para uma teoria da participação da sociedade civil: a primeira é que, se introduzimos a democracia como variável, a política carece tanto do ator que age limitado pela autorização recebida e ao qual nos habituamos a chamar de representante quanto do ator livre que, ao invés de delegar a representação dos seus atos, decide responsabilizar-se por eles. Se o ator que age por sua própria conta fala em nome de outros atores, não deixa de haver representação, ainda que, nesse caso, ela se dê por identificação. Neste artigo, denominarei esse tipo de relação de representação por afinidade. No entanto, antes de apresentar os principais elementos dessa concepção de representação, abordarei a maneira como as idéias de eleição, monopólio e territorialidade foram agregadas à idéia de autorização no decorrer do debate. 
A teoria da representação pode ser dividida em dois grandes momentos, um primeiro, no qual a representação assumiu uma feição lógico-hipotética e no qual não há uma instituição política capaz de instituir o ato da representação. O debate sobre o assunto, então, se reduziu à discussão acerca da legitimidade do contrato social no processo de constituição do governo. O contrato social, nesse caso, constitui um ato meramente hipotético. O segundo momento da emergência da centralidade da representação esteve pautado por uma teoria sobre o revezamento dos governantes no poder, teoria esta que tem origem no republicanismo (Manin, 1997:44-45). Como Bernard Manin aponta de forma adequada, o republicanismo europeu jamais trabalhou com o conceito de eleição e sim com a idéia do sorteio enquanto fundante do revezamento dos indivíduos no poder. Manin mostra como o conceito de eleição foi sendo trazido progressivamente para o centro da teoria republicana, levando a uma mudança de concepção: em vez da legitimidade do revezamento dos indivíduos no poder, a teoria da representação passou a se preocupar com que aquele que ocupasse o poder detivesse a autorização de todos os indivíduos, transformando a representação em uma forma de governo (idem:92) ${ }^{4}$. No entanto, o autor deixa de tratar de uma questão que adquiriu centralidade na segunda metade do século XX: a maneira como as eleições, enquanto instrumento da representação, adquiriram status monopolista no interior de um determinado território.

Os conceitos de monopólio e territorialidade não são inerentes à idéia de representação. Eles só foram associados a ela no decorrer do processo de consolidação do Estado moderno. A princípio, as instituições representativas, no fim do período medieval e no começo do período moderno, operavam por superposição de soberania, isto é, elas decidiam em relação a algum aspecto da ordem política e tal decisão era tomada em diversos lugares, gerando uma superposição de soberanias ou formas de representação (Held, 1995). O processo através do qual a representação adquire o monopólio da capacidade de deliberação no interior do sistema político está ligado ao surgimento, fortalecimento e desenvolvimento do Estado moderno (Tilly, 1986; 1993; Weber, Gerth e Mills, 1958). Nesse processo, que inicialmente teve lugar nas esferas coercitiva e administrativa, o Estado moderno vai se tornar a única instituição com capacidade de ação no interior do território. Além do mais, vale a pena lembrar que a construção do Estado moderno não foi apenas a construção de uma ordem estatal homogênea, mas foi também um processo de homogeneização das comunidades políticas 
(Anderson, 1991). Em cada unidade territorial na qual ocorreu o estabelecimento de uma entidade estatal única, ocorreu também a unificação da linguagem e da comunidade política (idem). No caso da França, por exemplo, a Revolução Francesa aboliu o provençal e o Parlamento da Provence, que esteve em operação até 1789. Assim, é importante perceber que não há uma relação conceitual ou institucional entre a transformação da representação na forma principal de operação das instituições políticas e sua modificação em autorização na única forma de organização do sistema político no interior dos estados modernos. Essa última está ligada apenas à maneira como os estados europeus se unificaram em torno de uma única comunidade política homogênea.

Nesse sentido, posso concluir essa breve digressão sobre representação na política moderna apontando para o fato de que, na sua origem, ela envolve a idéia de representação por afinidade, dimensão paulatinamente substituída pela idéia de monopólio da representação no interior do território. Na medida em que o conceito monopolista entrou em crise, diversos autores lançaram outros tipos de entendimento, entre os quais vale a pena destacar a representação virtual, a com expansão temporal e a discursiva. Na seção seguinte, analisarei e criticarei cada um desses conceitos antes de explicar como poderíamos reconstruir o conceito de representação por afinidade.

\section{A CRÍTICA DO CONCEITO DE REPRESENTAÇÃO PELA TEORIA POLÍTICA CONTEMPORÂNEA}

Diversos autores no campo da teoria política apontaram recentemente os limites da forma como a representação opera nas democracias contemporâneas e, ao mesmo tempo, tentaram concebê-la de uma maneira distinta. Nesta seção, abordarei detalhadamente três tentativas de propor uma nova concepção de representação: a virtual, feita por Houtzager, Gurza Lavalle e Castello; a de representação além da dimensão eleitoral, feita por Nadia Urbinati; e a discursiva, feita por John Dryzek.

A primeira dessas tentativas procura abordar a crise da representação pela ótica do seu estatuto dual. Houtzager, Gurza Lavalle e Castello, em um artigo recente sobre o assunto, relacionam os seus problemas atuais a uma dualidade constitutiva entre a formação da vontade e sua institucionalização. Para os autores, a história política moderna tem sido dominada por essa dualidade entre 
"[...] a autonomia do representante versus o mandato dos representados, o componente institucional legal da representação versus o seu componente substantivo ou de formação da vontade, o peso da delegação ou elemento fiduciário versus o peso da autorização ou elemento do consentimento [...]" (Gurza Lavalle, Houtzager e Castello, 2006:56, ênfases no original).

Assim, não haveria nada de novo no que diz respeito à crise da representação, e, por isso, os autores buscam a solução dos problemas que eles apresentam em um autor clássico do pensamento anti-revolucionário, Edmund Burke. A obra de Burke tem dois componentes fundamentais: o primeiro deriva da sua condição de representante dos eleitores de Bristol. Em um discurso, ao ser eleito representante da cidade no Parlamento, Burke afirma que

“[...] a alegria e a glória do representante se dão a partir do momento em que ele estabelece a mais estreita união e correspondência e comunicação sem reserva com os seus eleitores [constituents]. Seus desejos devem ter um grande peso, suas opiniões, um grande respeito, seus negócios, uma atenção sem limites e, sobretudo, ele deve preferir o interesse deles [seus eleitores] ao seu próprio interesse. Mas a sua opinião sem preconceitos, o seu julgamento maduro e a sua consciência iluminada não devem ser sacrificadas para a vigência do julgamento deles [dos eleitores] nem para a de qualquer homem ou grupo de homens vivos [...]" (Burke, 1774, tradução do autor).

O discurso de Burke sobre a autonomia dos representantes no exercício do seu mandato, posição que prevalece na modernidade política, é exemplar (Pitkin, 1967; Manin, 1997). No entanto, dificilmente serve para o objetivo para o qual Gurza Lavalle, Houtzager e Castello parecem querer empregá-lo, o de ser uma defesa da representação virtual entendida como uma representação "[...] não formalmente reconhecida ou aceita" (Gurza Lavalle, Houtzager e Castello, 2006:89-90). Nesse caso, os autores parecem perder de vista a outra dimensão da obra de Burke na qual o conceito de representação virtual parece se aplicar mais fortemente, a da defesa da representação sem eleições das monarquias pré-Revolução Francesa.

Burke, em seu livro mais conhecido, Reflexões sobre a Revolução em França, encarrega-se de levar a uma radicalidade ainda maior o seu argumento no discurso para os eleitores de Bristol contra a correspondência entre exercício do mandato e eleição. Partilhando o verdadeiro hor- 
ror que a Revolução Francesa causou nas elites conservadoras européias, Burke argumenta não somente contra o regime no qual o povo é a origem da representação, o regime que está emergindo na França, mas também contra a própria idéia de que a única monarquia legítima seria a inglesa, porque apenas ela haveria assegurado a autorização dos representantes (Burke, 1982:55). Para Burke,

\begin{abstract}
"[...] em um ou outro momento, todos os fundadores de dinastia foram escolhidos pelos que os chamaram a governar, e pode-se sustentar a opinião de que todos os reinos da Europa foram, no passado, eletivos, com mais ou menos limitações no objeto de escolha [...] [Hoje, os reis adquirem a soberania][...] por uma ordem de sucessão fixa, de acordo com as leis de seu país, e enquanto as condições legais do pacto de soberania forem preenchidas [...] ele possuirá a sua coroa sem ter de se preocupar com a escolha da sociedade da revolução" (idem:56).
\end{abstract}

Não é difícil perceber, a partir da interpretação adequada das intenções de Burke, o tamanho do equívoco que é trazer essa discussão para o debate sobre a forma de representação instituída pela sociedade civil. Burke está, com toda a força do seu argumento, tentando estabelecer a legitimidade da representação não-eleitoral realizada pelos reis europeus ${ }^{5}$. Não existe qualquer dúvida de que, nessa discussão, ele foi derrotado e que o modelo inglês de legitimação da monarquia pelo Parlamento se generalizou para a Europa como um todo. Tal modelo é hoje limitado pela emergência de novos fenômenos como atores da sociedade civil ou formas de legitimidade discursivas. A questão, no entanto, é que, na ânsia de legitimar uma forma de representação pós-eleitoral, Gurza Lavalle, Houtzager e Castello acabam resgatando um argumento pela legitimidade da representação pré-eleitoral. Ao proceder assim, eles jogam fora a criança junto com a água do banho, não conseguindo propor um conceito de representação que vá além da autorização via eleição. Examinarei em seguida tentativas mais exitosas de justificar a representação não-eleitoral.

Nadia Urbinati (2006a) abriu uma segunda linha importante de reflexão em um livro recente sobre a democracia representativa, assim como em diversas outras contribuições ${ }^{6}$. O ponto de partida de Urbinati é avançar em relação à maneira como Hanna Pitkin abordou o conceito de representação, teorizando-o a partir dos diferentes usos linguísticos do termo. A autora resgata o método utilizado originalmente por Pitkin e acrescenta a ele um novo conjunto de utilizações do referido 
vocábulo. Para Urbinati, a concentração do conceito de representação em torno de questões como a autorização e a accountability

"[...] deixou de ser satisfatória devido a transformações na política doméstica e internacional. Cada vez mais atores internacionais, transnacionais e não-governamentais desempenham um papel importante na implementação de políticas públicas a favor dos cidadãos. Neste sentido, eles agem como representantes. Esses atores 'falam por', 'agem por' e 'defendem posições em nome de' indivíduos no interior do Estado nacional" (Urbinati, 2006b, tradução do autor).

Assim, através da utilização do mesmo método empregado por Pitkin, Urbinati lança luz sobre as formas não-eleitorais, mas legítimas de representação política. A questão que se coloca é: como justificar a legitimidade dessas novas formas de representação?

Urbinati faz duas contribuições importantes ao debate ao tentar justificar um conceito mais amplo. A primeira é mostrar que a eleição é uma entre as múltiplas dimensões da representação e da relação entre Estado e sociedade civil.

“No momento em que as eleições se tornaram um requisito indispensável e solene da legitimação política e da designação de magistrados, Estado e sociedade civil não puderam mais ser separados, e o desenho das fronteiras separando e conectando as suas esferas de ação tornou-se uma questão a ser permanentemente negociada e reajustada" (idem, tradução do autor).

Nesse sentido, diferentemente de Gurza Lavalle, Houtzager e Castello, Urbinati dá um passo à frente nesse debate ao mostrar que o problema da representação contemporânea está ligado à evolução das práticas políticas que tornam sua modalidade eleitoral uma maneira relevante, mas incapaz de dar conta da totalidade das relações de representação entre os atores sociais e o Estado.

A segunda contribuição de Urbinati ao debate é a sua tentativa de desvincular a relação entre soberania e representação, ao mostrar a inadequação da forma como Rousseau associou uma e outra dimensão. Segundo Urbinati

"[...] a teoria da incompatibilidade [entre a democracia e a representação] é filha adotiva da moderna concepção de soberania. Suas coordenadas conceituais assentam-se no cerne do constitucionalismo moder- 
no tal como elaborado por Montesquieu e Rousseau, os primeiros teóricos a argumentarem [por diferentes motivos] acerca da tensão insolúvel entre democracia, soberania e representação" (Urbinati, 2006a:6, tradução do autor).

Urbinati destaca o fato de o modelo rousseauniano da perda da soberania ser na realidade um modelo privatista. Na formulação bastante conhecida do "Contrato Social", Rousseau diz que o indivíduo ou é livre para exercer a sua própria soberania ou ele a delega a um outro e, ao fazê-lo, torna-se um escravo. Boa parte das teorias da participação política estão baseadas no contraste proposto por Rousseau, que, na verdade, tem como modelo não a representação pública e sim a forma contratual e privada de alienação de direitos (Urbinati, 2003). Este é justamente o problema com a crítica da representação vinculada à soberania em Rousseau: ele não consegue evoluir de um modelo privado para um público e se prende a uma forma elementar de não-delegação da soberania. No entanto, todas as formas de participação, até mesmo as mais diretas possíveis, implicam em delegação de soberania, e a questão é justamente pensar quais são as suas formas políticas.

Ambas as contribuições de Urbinati à questão da representação são inspiradas em Condorcet e na substituição do conceito de soberania pelo conceito de julgamento político ${ }^{7}$. Este envolve a construção de um cenário hipotético de realizações políticas que podem ou não se confirmar. Enquanto tal, ele requer uma abrangência temporal mais ampla para a relação entre o representante e o representado na qual a eleição seria apenas um momento (Urbinati, 2006a:199). O elemento novo da crítica de Urbinati seria uma tentativa de integrar a eleição no interior de um conceito mais amplo de julgamento político que envolveria outras temporalidades e outras formas não-eleitorais de representação e até mesmo a possibilidade da revogação da autorização concedida. Apesar do brilhantismo da sua crítica às limitações do conceito eleitoral de representação, a contribuição de Nadia Urbinati à discussão padece de um problema: ela não consegue pluralizar as fontes que geram o julgamento político de modo a integrar as novas formas de participação ao conceito que ela propõe. Baseada em Condorcet, ela proporá duas formas de ampliação da representação: a ampliação temporal, através do referendum revogativo do mandato, e a possibilidade de revisão das leis (idem:205-206). Ambas as propostas são importantes e já constituem parte da institucionalidade do mundo anglo-saxão. No entanto, a questão que torna a solução proposta por Urbinati vulnerávelé 
que ela não consegue incorporar, na sua perspectiva de representação política, nenhuma nova institucionalidade capaz de dar vazão seja à advocacia ${ }^{8}$, seja à representação da sociedade civil.

John Dryzek foi, entre os três autores, o que melhor percebeu as antinomias da forma contemporânea de representação. Já no seu livro Deliberative Democracy and Beyond, o autor propôs uma diferenciação relevante entre a representação de pessoas e interesses e a de discursos, visando diferenciar sua abordagem da deliberação democrática daquela proposta por John Rawls, que associa o constitucionalismo liberal à democracia deliberativa. Para Dryzek, há dimensão discursiva ignorada pelo constitucionalismo liberal que precisa ser elaborada em separado (Dryzek, 2000:19), e seria necessário um desenho da dimensão discursiva que, para além das eleições, fosse capaz de contemplar novas formas de discurso não necessariamente expressas pela via eleitoral (idem). Nesse sentido, a preocupação inicial da obra de Dryzek é separar a dimensão discursiva da dimensão eleitoral e pensar nos desenhos institucionais que a pluralidade discursiva é capaz de gerar.

Em alguns escritos posteriores, Dryzek abordará a crítica da representação como a crítica à exclusividade do demos, o tema deste artigo (Dryzek e Niemeyer, 2006). De forma semelhante à crítica de Urbinati, Dryzek aponta que a concepção eleitoral de representação supõe que a categoria demos enquanto agregação da totalidade dos indivíduos não seria capaz, através do sufrágio, de reunir as múltiplas dimensões da política moderna. Seria, justamente, essa dimensão que estaria sendo posta em xeque pela emergência de uma pluralidade de discursos não necessariamente expressos pela via eleitoral (idem:6). A solução de Dryzek é pensar a possibilidade de criação de uma câmara de discursos que exista ao lado das formas de representação dos indivíduos. Seria necessário identificar um conjunto de discursos diferentes e dar a eles vazão em uma câmara onde estivessem em oposição uns contra os outros. Como apontam Dryzek e Niemeyer, "Membros da câmara de discursos não poderiam ser eleitos, porque se o fossem passariam a representar indivíduos. Outra opção seria a seleção aleatória de membros [dessa câmara]" (ibidem). A proposta de Dryzek avança em relação à de Urbinati em uma direção importante, qual seja, a de perceber que os novos atores e as novas formas de associação colocam em xeque o funcionamento da representação baseada no demos enquanto instância monopolista de agregação de indivíduos. Dryzek dá um passo adiante ao pensar uma câmara de discursos e, portanto, ao romper com a idéia 
habermasiana de uma esfera pública informal de feição não-institucional, tal como eu já havia proposto (Avritzer, 2002). No entanto, a proposta de Dryzek tem três limitações importantes: em primeiro lugar, separa representação de indivíduos daquela de idéias, o que me parece um pouco difícil de ser feito, e ignora o fato de que não se representam só discursos, mas também interesses, valores e idéias. Em segundo lugar, tal como Urbinati, mas equivocadamente, ele supõe que a sociedade civil se limita à advocacia de idéias quando, na verdade, se percebe cada vez mais um associativismo ligado a interesses e valores e propostas específicas de políticas públicas (Warren e Castiglioni, 2006). O conceito de advocacia parece insuficiente para lidar com esse vasto campo de representação não-eleitoral, uma vez que os atores não-governamentais freqüentemente se engajam em políticas específicas, criando novas arenas políticas nas quais suas idéias possam ser implementadas. Em terceiro lugar, Dryzek ignora que a maior parte das vezes nas quais a sociedade civil está exercendo funções de representação, ela está apoiada em organismos deliberativos com os quais divide prerrogativas com membros do Poder Executivo ${ }^{9}$ e, portanto, a criação de uma câmara unicamente discursiva não resolveria o problema da legitimidade da representação. A questão seria justificar ou negar a representação específica que a sociedade civil exerce em arenas deliberativas. Na próxima seção, proporei uma forma diferente das expostas até aqui de se pensar a legitimidade da representação da sociedade civil.

\section{A DIMENSÃO NÃO-ELEITORAL DA REPRESENTAÇÃO: A REPRESENTAÇÃO POR AFINIDADE}

Parece claro que o ponto de partida para a construção de um conceito mais amplo de representação que envolva tanto a sua dimensão eleitoral, quanto a sua dimensão não-eleitoral, reside no questionamento da relação direta entre representação e soberania. Se é verdade que ambos os conceitos estão em crise, as duas crises são motivadas por fenômenos completamente diferentes. No caso da soberania centrada no Estado moderno, tudo indica que a sua crise é inexorável, sendo causada por um enfraquecimento paulatino do Estado e pelo papel cada vez maior de instituições internacionais no campo da economia e das trocas internacionais. Em todos esses casos, a presença de atores com origem fora do Estado nacional é inevitável (Held, 1995; 2003). Já, no caso da representação, a questão é como reconstruí-la de modo a integrar seu elemento eleitoral com as diversas formas de advocacia e participação que têm origem extra-eleitoral. É desejável que uma reconstru- 
ção adequada do conceito de representação reforce tanto os seus elementos eleitorais quanto os não-eleitorais e, para isso, é importante ter como ponto de partida que a situação na qual a representação vai operar daqui em diante é a das múltiplas soberanias (Held, 1995). Tanto a contribuição de Urbinati pensando o político como um contínuo no qual a eleição é um momento relevante, ainda que apenas um momento, quanto a contribuição de Dryzek, pensando a necessidade de institucionalizar novas formas de discurso, são contribuições de interesse. No entanto, cada uma delas sofre de uma deficiência importante: no caso de Urbinati, a incapacidade de pensar a institucionalidade do continuum da representação, e, no caso de Dryzek, a incapacidade de pensar os elementos não-discursivos das novas formas de representação. Uma combinação da contribuição dos dois autores me parece mais adequada.

Para se pensar uma maneira de articular essas novas dimensões, é necessário pensar o contexto no qual a representação pode operar e no qual irão conviver a representação eleitoral e a representação da sociedade civil. É importante também entender qual é o papel da autorização na criação de legitimidade nesse novo contexto. A meu ver, o elemento mais importante desse debate é perceber que existem diversos tipos de autorização relacionados a três papéis políticos diferentes: o de agente, o de advogado e o de partícipe. Em todos os três casos, há o elemento do "agir no lugar de", tão ressaltado por Hanna Pitkin. O importante é, no entanto, perceber que o "agir no lugar de" varia de perspectiva e pode ser justificado de diferentes maneiras. No caso do agente escolhido pelo processo eleitoral - o caso clássico de representação-, ele não precisa ser discutido em detalhes neste artigo (Pitkin, 1967). Mas as mudanças recentes são essenciais nos dois últimos casos, e vale a pena discutir a sua legitimidade.

O caso da advocacia de causas coletivas vai além das discussões feitas por Hobbes a Hanna Pitkin sobre o papel do advogado ou ativista. Até muito recentemente, o advogado era escolhido pela própria pessoa ou conjunto de pessoas e agia a partir de instruções precisas destes atores. Nas últimas décadas, emergiu um conceito de advocacia de causas públicas ou privadas que prescinde dessa dimensão. Organizações nãogovernamentais que trabalham causas fora dos seus estados nacionais defendem atores que não as indicaram para tal função, como é o caso da Anistia Internacional ou do Greenpeace. Aí, a advocacia de temas parece prescindir da escolha ou de qualquer outro tipo de autorização. 
Existem casos ainda mais problemáticos para uma teoria da representação, como aqueles em que algumas organizações de direitos das mulheres defendem a autonomia das mulheres em países nos quais elas não têm direito e, se consultadas, provavelmente diriam que não são a favor desses direitos (Kandiyoti, 1991). Em todas essas circunstâncias, não é a autorização, e sim a afinidade ou identificação de um conjunto de indivíduos com a situação vivida por outros indivíduos que legitima a advocacia. Assim, pode-se dizer que a mulher norte-americana ou européia tem uma relação de identificação com a situação de uma mulher indiana ou muçulmana, mas certamente não detém a autorização para representá-las. Na melhor das hipóteses, o que se pode presumir é que, em condições abertas de troca de informações, os atores envolvidos teriam posições diferentes em relação a seus próprios direitos, o que, de toda maneira, é apenas uma suposição. Nesse sentido, o elemento central da advocacia de temas não é a autorização, e sim uma relação variável no seu conteúdo entre os atores e os seus representantes. Se voltarmos a Cícero e sua descrição do papel do procurador, percebemos que a identificação com a causa se tornou mais importante que a autorização explícita para representá-la. Nesse caso, o que as ONGs internacionais estão representando é um discurso sobre os direitos das mulheres em geral e não um conjunto específico de pessoas.

O terceiro caso é o da representação da sociedade civil. Esta, que tem se tornado muito forte nas áreas de políticas públicas no mundo em desenvolvimento, se dá a partir da especialização temática e da experiência. Organizações criadas por atores da sociedade civil e que lidam por muito tempo com um problema na área de políticas sociais tendem a assumir a função de representantes da sociedade civil em conselhos ou outros organismos encarregados das políticas públicas. Esta situação é diferente das outras duas: de um lado, há freqüentemente, especialmente no Brasil, eleições para esses representantes, mas o eleitorado tem características muito específicas ${ }^{10}$. Há um grupo no qual está a origem da representação exercida por esses representantes, mas esse grupo pode incluir ou não todas as associações ligadas ao tema ou mesmo não estar organizado em associações. Em um caso, estamos falando de uma representação quase coletiva e, no outro, de uma forma coletiva e não-institucionalizada de ação que gera a representação. Este último não possui as características da igualdade matemática da soberania, tão cara à idéia de representação eleitoral, e não possui o elemento monopolista territorial na medida em que partilha a capacidade de decisão com outras instituições presentes no território. O importante em 
relação a essa forma de representação é que ela tem sua origem em uma escolha entre atores da sociedade civil, decidida freqüentemente no interior de associações civis. Estas exercem o papel de criar afinidades intermediárias, isso é, elas agregam solidariedades e interesses parciais (Warren, 2001). Ao agregarem estes interesses, elas propiciam uma forma de representação por escolha que não é uma representação eleitoral de indivíduos ou pessoas. A diferença entre a representação por afinidade e a eleitoral é que a primeira se legitima em uma identidade ou solidariedade parcial exercida anteriormente.

O que fornece a legitimidade da representação por afinidade? A legitimidade do representante entre outros atores que atuam da mesma maneira que ele. Neste sentido, a questão das identidades parciais na política reassumem um novo papel que foi, de alguma maneira, abolido pela política moderna ${ }^{11}$. A pragmática da legitimação é diferente, na medida em que a legitimação se dá pela relação com o tema. É ela que gera a legitimidade e não o contrário, como na representação eleitoral. O Quadro 1 pretende sintetizar as diferentes formas de representação discutidas aqui:

Quadro 1

Formas de Representação na Política Contemporânea

\begin{tabular}{|l|l|l|l|}
\hline $\begin{array}{l}\text { Tipo de } \\
\text { Representação }\end{array}$ & $\begin{array}{c}\text { Relação com o } \\
\text { Representado }\end{array}$ & $\begin{array}{c}\text { Forma de } \\
\text { Legitimidade da } \\
\text { Representação }\end{array}$ & $\begin{array}{c}\text { Sentido da } \\
\text { Representação }\end{array}$ \\
\hline Eleitoral & $\begin{array}{l}\text { Autorização atra- } \\
\text { vés do voto }\end{array}$ & Pelo processo & $\begin{array}{l}\text { Representação de } \\
\text { pessoas }\end{array}$ \\
\hline Advocacia & $\begin{array}{l}\text { Identificação com } \\
\text { a condição }\end{array}$ & $\begin{array}{l}\text { Pela finalidade } \\
\text { discursosentação de }\end{array}$ \\
\hline $\begin{array}{l}\text { Representas } \\
\text { sociedade çãa da }\end{array}$ & $\begin{array}{l}\text { Autorização dos } \\
\text { atores com expe- } \\
\text { riência no tema }\end{array}$ & $\begin{array}{l}\text { Pela finalidade e } \\
\text { pelo processo }\end{array}$ & $\begin{array}{l}\text { Representação de te- } \\
\text { mas e experiências }\end{array}$ \\
\hline
\end{tabular}

Elaboração do autor.

Se pensarmos esses três aspectos da representação, é possível perceber como se pode teorizar a representação de uma maneira diferente. Em primeiro lugar, a representação eleitoral deve significar a abertura de um quadro de relacionamento entre diferentes tipos de soberania (Young, 2000) ${ }^{12}$. Nesse sentido, a eleição decide uma maneira através da qual corpos representativos se relacionarão com a advocacia e a representação da sociedade civil. Esta relação pode ser mais ou menos 
complementar, dependendo da proposta política eleita, ainda que no Brasil a relação entre representação eleitoral e não-eleitoral tenha sido um dos elementos comuns dos últimos governos. No caso do Brasil, a eleição tem determinado também a maneira como um tipo de representação é capaz de legitimar o outro. Assim, no governo Fernando Henrique Cardoso, os presidentes de conselhos nacionais eram indicados pelo presidente, ao passo que, no governo Luiz Inácio Lula da Silva, os presidentes de conselhos nacionais são eleitos pela sociedade civil (Avritzer, no prelo). Isso mostra que uma forma de representação pode tanto emprestar legitimidade para a outra como também questioná-la.

Um aspecto importante dessas novas formas é que elas não aparecem puras na política contemporânea. As eleições continuam sendo a maneira mais democrática de escolha dos representantes, mas, uma vez eleitos, estes se encontram com a advocacia de temas e a representação da sociedade civil. Aqueles representantes que ignoram essa representação, seja no âmbito nacional, seja no internacional, tendem a se deslegitimar entre os seus próprios eleitores e têm sido muitas vezes incapazes de implementar a sua própria agenda ${ }^{13}$. Assim, é cada vez mais freqüente o encontro entre representantes eleitos e advocacia de ONGs internacionais ou de representantes eleitos e representantes da sociedade civil em instituições híbridas (Avritzer e Pereira, 2005) no campo das políticas públicas. Tais encontros mostram que, diferentemente do suposto por Urbinati, o continuum da política assume formas institucionais diversas que devem ser parte da discussão e que, diferentemente do suposto por Dryzek, põem conjuntamente representantes eleitos por diversos processos. Nesse sentido, a questão colocada pela política contemporânea deve ser uma redução da preocupação com legitimidade dessas novas formas de representação e um aumento da preocupação sobre de que modo elas devem se sobrepor em um sistema político regido por múltiplas soberanias. O futuro da representação eleitoral parece cada vez mais ligado à sua combinação com as formas de representação que têm sua origem na participação da sociedade civil.

(Recebido para publicação em janeiro de 2007) (Versão definitiva em agosto de 2007) 


\section{NOTAS}

1. Esse dado referente ao ano de 2004 foi obtido somando-se a adesão aos orçamentos participativos nas cidades de São Paulo (80 mil pessoas), Porto Alegre (30 mil), Belo Horizonte (30 mil) e Recife ( 40 mil). O envolvimento de quase 200 mil pessoas em políticas participativas mostra que a participação é uma forma relevante de exercício da soberania política no Brasil hoje.

2. Esse é um aspecto fundante da teoria da representação desde os seus primórdios. A representação aparece em Locke e até mesmo em Rousseau associada a um princípio de igualdade matematicamente estabelecido, a partir do qual o voto de cada indivíduo tem exatamente o mesmo peso. Vide Rousseau (1997).

3. Otto Gierke (1987) chamou, pela primeira vez, atenção para o fato de que a estrutura de soberania do final do período medieval era uma estrutura de superposição de entidades soberanas. Estado, governos locais e instituições como a Igreja católica decidiam, simultaneamente, sobre questões distintas no mesmo território sem que nenhuma das instituições reivindicasse um monopólio total da soberania naquele território. A associação entre território e monopólio só surge com o Estado moderno. David Held (1995) recentemente observou um retorno da concepção medieval de superposição de soberanias a partir da criação da Comunidade Européia.

4. Discutir o debate em torno da representação não é o mesmo que discutir as virtudese os problemas do governo representativo. A diferença reside na questão do monopólio da representação entre aqueles que defendem o governo representativo como a única forma de governo. O estudo de Bernard Manin concentrou-se mais na segunda dimensão entendida como a autonomia dos governantes em relação à vontade dos representados (Manin, 1997:6). Nadia Urbinati critica a redução do debate sobre a representação ao funcionamento do governo representativo ao afirmar que é um erro supor que a singularidade da representação reside nas eleições. Para ela, estas são parte do processo de estabelecimento da representação e, neste sentido, o governo representativo não pode ser reduzido à representação eleitoral. Vide Urbinati (2006a:9).

5. Vale a pena lembrar também que, durante o processo de independência dos Estados Unidos, a Coroa inglesa utilizou o conceito de representação virtual para defender que os interesses dos cidadãos das 13 colônias estavam representados no Parlamento inglês (vide Wood, 1969:180). A discussão inglesa mostra a correção da reconstrução do conceito de representação por Manin, que postula a identidade entre representação e autorização por todos os indivíduos.

6. Vide também uma série de artigos publicados nas revistas Political Theory e Constellations. Nesses artigos, Urbinati tratou de questões como advocacia e representação e a crítica ao modelo de representação presente na obra de Rousseau. Vide Urbinati (2000; 2003; e 2006b).

7. Um dos pareceristas deste artigo discordou do argumento aqui apresentado, defendendo que a substituição do conceito de vontade pelo conceito de juízo proposto por Urbinati não implicaria na desvinculação entre soberania e representação. Este autor discorda desta interpretação não apenas pelo fato de a autora explicitamente afirmá-lo (Urbinati, 2006a:6) mas também porque é muito difícil que o conceito de juízo se articule com o de soberania, já que esta última demanda uma autorização explícita 
para "agir no lugar de". O conceito de juízo, devido a sua extensão temporal, implica em cada cidadão se colocar no lugar do soberano e julgá-lo. Nesse sentido, há sim uma desvinculação entre soberania e representação. Vide Urbinati (idem:105).

8. Um dos pareceristas deste artigo sugeriu corretamente que a tradução do termo advocacy por advocacia não gera o mesmo sentido na língua portuguesa. Ele ou ela sugere, no lugar, militância ou ativismo. Apesar da correção da observação lingüística, optei por manter advocacia na maior parte do texto, porque militância ou ativismo na língua portuguesa parecem mais ligados à intensidade de algumas formas de ação política de esquerda do que à exposição de idéias e de atores. Em algumas passagens nas quais advocacia me pareceu totalmente inadequado, acrescentei o termo ativismo.

9. Este é sem dúvida o caso do Brasil, mas parece ser o caso no mundo em desenvolvimento em geral. Formas de participação da sociedade civil no Peru, na Argentina, na Índia e até mesmo nos Estados Unidos, nos chamados programas habitat, funcionam dessa maneira. A exceção, e que pode ser o caso que Dryzek tem em mente, são as reuniões paralelas das Nações Unidas nas quais a sociedade civil se reúne separadamente dos organismos que exercem a representação de países. Vide Panfichi (2003).

10. Existem diferentes casos de eleições entre os quais devem ser destacadas as eleições para o conselho de habitação de São Paulo, durante a gestão Marta Suplicy, em que votaram mais de 30 mil pessoas. Existem também casos nos quais alguns conselhos chegaram a normatizar em profundidade o que é um representante da sociedade civil, como o conselho de saúde da cidade. Vide Avritzer (2004).

11. Até o começo da era moderna, todas as formas de representação de interesses eram particulares por definição. As diferentes formas de representação corporativa que sobreviveram em alguns países da Europa até o começo do século XIX são um bom exemplo das formas de representação particular. O Estado moderno dissolveu-as na representação dos indivíduos, supondo que esta diluiria os interesses particulares.

12. Iris Young, em seu livro Inclusion and Democracy, tratou da idéia da representação como uma relação, mas de um modo distinto daquele que estamos propondo aqui. Para ela, a relação de tipos diferentes envolvida na representação limita-se a diferentes tipos de relação entre o representante e as suas bases. Vide Young (2000:128).

13. Entre os exemplos mais importantes, podemos destacar a questão dos direitos da mulher em diversos países do mundo árabe e questões ambientais em muitos países, entre os quais o Brasil. As audiências públicas introduzidas pelo governo Lula em questões com forte impacto ambiental, como a construção da BR-163 e a transposição das águas do rio São Francisco, são um exemplo da necessidade de governos eleitos se legitimarem para implementar políticas em áreas como o meio ambiente. 


\section{REFERÊNCIAS BIBLIOGRÁFICAS}

ABERS, Rebecca N. e KECK, Margareth E. (2006), “Muddy Waters: Decentralization, Coordination and Power Struggle in the Brazilian Water Management Reform". International Journal for Urban and Regional Research, vol. 30, no 3, pp. 601-622.

ANDERSON, Benedict. (1991), Imagined Communities: Reflections on the Origin and Spread of Nationalism (2a ed.). London/New York, Verso.

AVRITZER, Leonardo. (2002), Democracy and the Public Space in Latin America. Princeton, Princeton University Press.

(ed.). (2004), A Participação em São Paulo. São Paulo, Editora Unesp.

. (2006), “New Public Spheres in Brazil”. International Journal of Urban and Regional Research, vol. 30, no 3, pp. 623-637.

(no prelo), A Participação Social no Nordeste. Belo Horizonte, Editora da UFMG.

e PEREIRA, Maria de Lourdes Dolabela. (2005), “Democracia, Participação e Instituições Híbridas". Teoria \& Sociedade, número especial, pp. 16-41.

BURKE, Edmund. (1774), Speech to the Electors of Bristol at the Conclusion of the Poll. Disponível em: http://www.ourcivilisation.com/smartboard/shop/burkee/ extracts/chap4.htm, acessado em 15/7/2007.

. (1982), Reflexões sobre a Revolução em França. Brasília, Editora da UnB.

CÍCERO. (1942), Oratorium. Cambridge, Loeb Classical Library.

COELHO, Vera Schattan R. P. (2004), “Conselhos de Saúde enquanto Instituições Políticas: O Que Está Faltando?”, in V. S. R. P. Coelho e M. Nobre (orgs.), Participação e Deliberação: Teoria Democrática e Experiências Institucionais no Brasil Contemporâneo. São Paulo, Editora 34, pp. 255-269.

et alii. (2006), Participação e Distribuição de Serviços Públicos de Saúde no Município de São Paulo. Relatório de pesquisa. Cebrap, São Paulo.

COHEN, J. e SABEL, Charles. (2005), “Global Democracy”. NYU Journal of International Law and Politics, vol. 37, no 4, pp. 763-797.

CUNHA, Eleonora S. M. (2004), Aprofundando a Democracia: O Potencial dos Conselhos de Políticas e Orçamentos Participativos. Dissertação de mestrado. Departamento de Ciência Política, UFMG, Belo Horizonte.

DRYZEK, John. (2000), Deliberative Democracy and Beyond. Oxford, Oxford University Press.

e NIEMEYER, Simon. (2006), Discursive Representation. Trabalho apresentado no workshop Rethinking Democratic Representation. University of British Columbia, 18-19 de maio.

GIERKE, Otto. (1987) [1960], Political Theories of the Middle Age. Boston, Beacon Press.

GURZA LAVALlE, Adrian, HOUTZAGER, Peter e CASTELlO, Graziela. (2006), “Representação, Pluralização da Representação e Sociedade Civil". Lua Nova, no 67, pp. 49-103.

HELD, David. (1995), Democracy and the Global Order. Cambridge, Polity Press. 
. (2003), Global Covenant: The Social Democratic Alternative to the Washington Consensus. Cambridge, Polity Press.

HOBBES, Thomas. (1991), Leviatã ou Matéria, Forma e Poder de um Estado Eclesiástico e Civil. São Paulo, Abril Cultural.

KANDIYOTI, Deniz. (1991), "Women, Islam and the State". Middle East Report, no 173, pp. 9-14.

MANIN, Bernard. (1997), The Principles of Representative Government. Cambridge, Cambridge University Press.

MANSBRIDGE, Jane. (2003), "Rethinking Representation". American Political Science Review, vol. 97, no 4, pp. 515-528.

PANFICHI, Aldo. (2003), Sociedad Civil, Esfera Pública y Democratización en América Latina: Andes y Cono Sur. México, Fondo de Cultura Económica/Universidad Veracruzana.

PITKIN, F. Hanna. (1967), The Concept of Representation. Berkeley, University of California Press.

(1993), "Hobbes Concept of Representation", in P. T. King (ed.), Thomas Hobbes: Critical Assessments: Politics and Law. London, Routledge (vol. 3).

ROUSSEAU, Jean-Jacques. (1997) [1762], The Discourses and Other Early Political Writings. Cambridge, Cambridge University Press (edição de Victor Gourevitch).

TILLY, Charles. (1986), The Contentious French. Cambridge, Harvard University Press. (1993), Coercion, Capital and European States: AD 990-1992. Oxford, Blackwell (Coleção Studies in Social Discontinuity).

URBINATI, Nadia. (2000), “Representation as Advocacy: A Study of Democratic Deliberation". Political Theory, vol. 28, no 6, pp. 758-786.

. (2003), "Continuity and Rupture: The Power of Judgment in Democratic Representation". Constellations, vol. 12, no 2, pp. 194-222.

_. (2006a), Representative Democracy. Chicago, The University of Chicago Press.

(2006b), Representation. Trabalho apresentado no workshop Yale Political Theory. Yale University, 9 de novembro.

WARREN, Mark. (2001), Democracy and Associations. Princeton, Princeton University Press.

e CASTIGLIONI, Dario. (2006), Rethinking Representation: Eight Theoretical Issues. Trabalho apresentado no workshop Rethinking Democratic Representation. University of British Columbia, 18-19 de maio.

WEBER, Max, GERTH, Hans H. e MILLS, C. Wright. (1958), From Max Weber: Essays in Sociology. Oxford, Oxford University Press.

WOOD, Gordon S. (1969), The Creation of the American Republic, 1776-1787. Chapel Hill, The University of North Carolina Press.

YOUNG, Iris M. (2000), Inclusion and Democracy. Oxford, Oxford University Press. 


\section{ABSTRACT \\ Civil Society, Participative Institutions, and Representation: From Authorization to Action Legitimacy}

In democratic Brazil, political participation has been characterized by the enlargement of civil society's presence in public policies. Such presence generated a series of institutions with the participation of civil society and state actors in the areas of social welfare, health and urban policies. Within these institutions, it began to happen what we can call an institutionalized representation of civil society. This representation is characterized by the inexistence of an explicit requirement of authorization, and the absence of a structure of territorial monopoly in the representation carried out by the actors of civil society. Representation by affinity is proposed as a manner of associating parliamentary representation and representation of civil society.

Key words: civil society; representation; authorization

\section{RÉSUMÉ}

Société Civile, Institutions Participatives et Représentation. De l'Autorisation à la Légitimité de l'Action

Dans le Brésil démocratique, la participation politique est marquée par une plus grande présence de la société civile dans le domaine des politiques publiques. Cette présence a engendré une série d'institutions où participent la société civile et des acteurs des États agissant sur le terrain de l'assistance sociale, de la santé et des politiques urbaines. Ces institutions ont fait apparaître ce qu'on peut appeler une représentation institutionnalisée de la société civile, dont les caractères sont tout d'abord l'absence explicite d'autorisation ainsi que l'absence de structure de monopole territorial dans la représentation effectuée par des acteurs de la société civile. Dans cet article, on cherche à discuter une façon de penser la légitimité de cette représentation en proposant la représentation par affinités comme susceptible d'associer représentation parlementaire et représentation de la société civile.

Mots-clé: société civile; représentation; autorisation 